Prof. Dr. Qiang Zhen, Dr. Sajid Bashir, Dr. Jingbo Louise Liu

\section{Nanostructured Materials for}

\section{Next-Generation Energy}

\section{Storage and Conversion}

This Volume focuses on the fundamentals related to batteries using the latest research in the field of battery physics, chemistry, and electrochemistry. The research summarized in this book by leading experts is laid out in an easy-to-understand format to enable the layperson to grasp the essence of the technology, its pitfalls and current challenges in high-power Lithium battery research. After introductory remarks on policy and battery safety, a series of monographs are offered related to fundamentals of lithium batteries, including theoretical modeling, simulation and experimental techniques used to characterize electrode materials, both at the material composition, and also at the device level. The different properties specific to each component of the batteries are discussed in order to offer tradeoffs between power and energy density, energy cycling, safety and, where appropriate, end-of-life disposal. Parameters affecting battery performance and cost, longevity using newer metal oxides, different electrolytes are also reviewed in the context of safety concerns and in relation to the solid-electrolyte interface. Separators, membranes, solid-state electrolytes, and electrolyte additives are also reviewed in light of safety, recycling, and high energy endurance issues. The book is intended for a wide audience, such as scientists who are new to the field, practitioners, as well as students in the STEM and STEP fields, as well as students working on batteries.
Prof. Krishan K. Chawla

\section{Composite Materials: Science and Engineering}

The fourth edition of Krishan Chawla's widely used textbook, Composite Materials, offers integrated and completely up-to-date coverage of composite materials. The book focuses on the triad of processing, structure, and properties, while providing a well-balanced treatment of the materials science and mechanics of composites. In this edition of Composite Materials, revised and updated throughout, increasing use of composites in industry (especially aerospace and energy) and new developments in the field are highlighted. New material on the advances in non-conventional composites (which covers polymer, metal and ceramic matrix nanocomposites), self-healing composites, self-reinforced composites, biocomposites and laminates made of metals and polymer matrix composites are included. Examples of practical applications in various fields are provided throughout the book, with extensive references to the literature. The book is intended for use in graduate and upper-division undergraduate courses and as a reference for the practicing engineers and researchers in industry and academia.

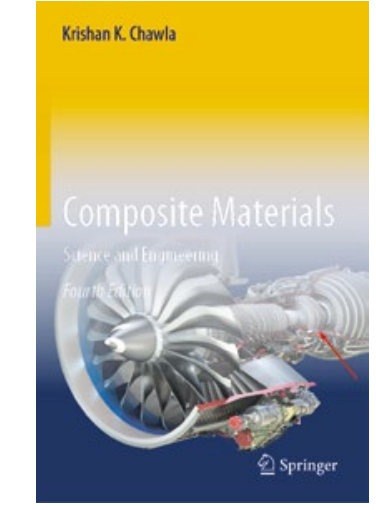

Springer International Publishing, 2019, Fourth Edition, 560 Pages, Hardcover, ISBN: 978-3-030-28982-9, 114,39 Euros, also available as eBook for 93,08 Euros at www.springer.com/booksellers
2019, 472 Pages, Hardcover, ISBN: 978-3-662-58673-0, 217,99 Euros, also available as eBook for 160,49 Euros at www.springer.com/booksellers

\section{Materials for}

Next-Generation

Energy Storage and

Conversion

Advanced Battery and Supercapactors

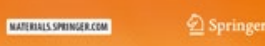

Springer Berlin Heidelberg, 